\title{
Smartphone: It's Use for Stress Coping in Spanish Teenagers
}

\author{
Blanca Espina-Jerez ${ }^{1}$, Sagrario Gomez-Cantarino ${ }^{1}$, Margarida Sim-Sim ${ }^{2}$ \\ ${ }^{1}$ Nursing Department, University of Castilla-La Mancha, Toledo, Spain \\ ${ }^{2}$ Nursing Department, University of Evora, Évora, Portugal
}

Email address:

blanca.espina@alu.uclm.es (B. Espina-Jerez), sagrario.Gomez@uclm.es (S. Gomez-Cantarino), msimsim@uevora.pt (M. Sim-Sim)

\section{To cite this article:}

Blanca Espina-Jerez, Sagrario Gomez-Cantarino, Margarida Sim-Sim. Smartphone: It's Use for Stress Coping in Spanish Teenagers. American Journal of Applied Psychology. Vol. 8, No. 1, 2019, pp. 8-13. doi: 10.11648/j.ajap.20190801.12

Received: February 6, 2019; Accepted: March 12, 2019; Published: April 1, 2019

\begin{abstract}
Nowadays, smartphones are becoming the most generalized technological device on the planet, and Spain is the European leader in smartphones market penetration. Objective: to analyze the differences between both kinds of coping (one directed to emotion and the other straight to the problem) in function of the kind of usage of the intelligent phone. Participants: The sample comprised 382 teenagers from whom 142 were discarded due to lacking certain inclusion criteria. A 54.6\% (131) belonged to the feminine gender and $45.4 \%$ (109) to the masculine. Results: showed differences between the cognitive avoidance coping and the excessive usage of the intelligent phone, the behavioral approximation and occasional and frequent usage. There are also differences between the sexes and all the strategies of coping directed to the problem, girls being the ones who used them the most. The interaction between age and the mobile phone usage for the variable emotional suppression is significant in 16-18-year-olds frequent users and at risk for 12 and 13 years old. Conclusion: for less adaptive coping ways (e.g. avoidance) teenagers are the most vulnerable to develop an excessive usage of the smartphone, while as those who confront the problems and difficulties from approximation tend to not use it in excess.
\end{abstract}

Keywords: Smartphone, Coping Behavior, Emotional Adjustment, Psychological Stress, Adolescents, Adolescence

\section{Introduction}

In Spain, the prevalence studies on the excessive use of the Smartphone estimate that it ranges between $0-38 \%$, depending on the scale and characteristics of the population studied [1]. In Spanish schools, more and more students spend their time between classes sending messages, talking on the phone, listening to music or using other of the innumerable applications a smartphone offers. Some of the behaviors facilitated by Smartphones have alarmed parents and family caregivers, furthermore, this issue is accompanied by a certain fear that this device will replace other habits or hobbies more traditional and considered more "positive" such as reading, talking with friends or playing in the street [2]. While younger adolescents see the smartphone as a kind of game console and adopt a playful attitude towards it [3], the older ones use it as an object which facilitates the construction of their individualization and the management of their family relationships and with their peers. Analyzing the use of the smartphone among teenagers, it is especially important not only because of the particularities of this stage of the life cycle, but also because they are usually among the first in trying new technologies and being more prone to innovate ways of using them [4].

Nevertheless, the mobile phone can be everything for them: social networks, downloads, music, photos and access to the internet, without parental or guardian control, which makes it a window open to the world and closed to the own in terms of privacy, but which educators and health professionals should not ignore $[2,4]$.

The current Smartphone is different from standard mobile phones in its operating system and equipment, with advanced features such as $3 \mathrm{G}$ or $4 \mathrm{G}$. They also offer multiple possibilities, such as instant messaging, access to email, navigation, cameras, video, etc. resembling a mobile personal computer, that's why they attract a large number of users $[1$, 5].

Some of the reasons explored for the use of the Smartphone have to do with entertaining, relieving stress [6], 
opening up new acting skills and promoting creativity and expression [7], so that it has become a daily practice for social interaction and relaxation purpose. In turn, it has been found that in reaction to stressful life events, the use of technologies helps to manage the state of mind, gain recognition and maintain social relationships [8]. However, spending too much time with it can lead to sleep disturbances, depression and stress $[9,10]$.

There are multiple terms to explain the phenomenon, because it has not yet been included as a diagnostic category. Researchers tend to talk about addiction [11-13] when referring to new communication technologies, but is it possible to clarify when their use becomes inappropriate? Many times, it starts from the contents a smartphone can offer (pornography, violence...). In other cases, frequency or duration are established as criteria, but it is evident that the number of hours is not enough to qualify a behavior as addictive [2].

However, more recent studies use terms such as excessive use $[14,15]$, problematic $[16-18]$ or pathological use (associated with significant damages and affections to oneself and others and in the person's daily activities) [19]. But all of them are exchangeable to describe more or less the same construct [20]. Bearing in mind the existing debate about the terms of behavioral addictions [21], this research adopts a more conservative expression, such as "excessive use", which can be problematic but also can have positive consequences or overcome the negative ones [22]. For this reason, the research will be from now on limited only to the term excessive use, in which the before mentioned terms are included (i.e., addiction, problematic use and pathological use).

\section{Aim of the Study}

The aim of the study is to describe the two types of coping (directed to the emotion and directed to the problem) depending on the use of the smartphone. We will study, two types of coping one directed to the emotional and the other directed to the problem, considering the use of the smartphone

\section{Subjects and Methods}

\subsection{Research Design}

This is a descriptive and cross-sectional study

\subsection{Research Setting}

The study is part of a post-graduate academic education in Psychology at a Spanish University. Data collection took place at Secondary Education School, Toledo, Spain.

\subsection{Subjects}

382 subjects were invited, considering the sequence of class lists, then a convenience sample of 240 was obtained.

\subsubsection{Inclusion Criteria}

It included those participants who had: 1) their own smartphone; 2) access to the Internet without control, in other words, a data rate plan; 3) age: between 12 and 18; 4) speaking and written comprehension of Spanish; 5) voluntary acceptance to participate in the survey; 6) acceptance of informed consent of parents, guardians or adults.

\subsubsection{Exclusion Criteria}

It excluded those who: 1) did not finish the questionnaires; 2) left without answering one or more questions; 3) did not describe the difficult situation on which the answers to the coping questionnaire are supported; 4) described it in a general way (e.g. problems with the studies).

\subsection{Data Collection}

The approach of the participants was carried out by the research team. It was done in group sessions of 20-30 students. The questionnaires were provided on paper. The survey and its implications were briefly explained, using a language adapted to the age of the participants. Time was left to resolve possible doubts. The anonymity of the participants and the use of the data for research purposes were guaranteed.

\subsection{Measuring Instruments}

Mobile Phone Problem Use for Adolescents (MPPUSA), adapted to Spanish [23]. Internal consistency with the original sample $\alpha=.970$ and with the study sample $\alpha=.890$.

Emotion Regulation Questionnaire (ERQ) [24], adapted to children and teenagers [25] and to Spanish [26]. Internal consistency: with the original sample RC $(\alpha=.790)$ and SE $(\alpha=.750)$ and with the study sample RC $(\alpha=.660)$ and SE $(\alpha=.670)$.

Coping Responses Inventory - Youth Form (CRI-YF) [27], adapted to Spanish and to teenagers [28]. Internal consistency: with the original sample: AACognitive $(\alpha=.660)$, AABehavioral $(\alpha=.660)$, AECognitive $(\alpha=.580)$ y AEBehavioral $(\alpha=.530)$; with the study sample: AACognitive ( $\alpha=.680)$, AABehavioral $(\alpha=.670)$, AECognitive $(\alpha=.620)$ y AEBehavioral $(\alpha=.510)$.

\subsection{Ethical Considerations}

The study was submitted to regulatory procedures at the Secondary Education School, after being passed at the Master Commission of the University of Madrid. Data collection took place, after authorized by the management of the Secondary Education School, the students over 18 and the parents and guardians in case of being a minor. Participation was voluntary with a signed informed consent form.

\subsection{Data Analysis}

Subjects are described through descriptive statistics. Following normal distribution (i.e., K-S>.05) we opted for parametric tests. The statistical studies were carried out with IBM SPSS Statistics 20. 


\section{Results}

\subsection{Sociodemographic Data of the SUBJECTS}

The final sampling size was 240 adolescents: 131 girls (54.6\%) and 109 boys (45.4\%). The mean age according to the gender was $14.38(\mathrm{SD}=1.65)$ for boys and $14.45(\mathrm{SD}=$ 1.48) for girls (Table 1).

Table 1. Frequency and Percentage of Participants Depending on age and School Year.

\begin{tabular}{llll}
\hline Variables & Groups & f & \% \\
\hline \multirow{4}{*}{ Age } & 12 & 32 & 13.3 \\
& 13 & 41 & 17.1 \\
& 14 & 53 & 22.1 \\
& 15 & 52 & 21.7 \\
\hline
\end{tabular}

\begin{tabular}{llll}
\hline Variables & Groups & f & \% \\
\hline & 17 & 21 & 8.8 \\
& 18 & 4 & 1.7 \\
& $1^{\circ} \mathrm{ESO}^{1}$ & 50 & 20.8 \\
School Year & $2^{\circ} \mathrm{ESO}^{\text {E }}$ & 61 & 25.4 \\
& $3^{\mathrm{ESO}}$ & 54 & 22.5 \\
& $4^{\mathrm{o}} \mathrm{ESO}$ & 46 & 19.2 \\
& $1^{\circ}$ Bachillerato $^{2}$ & 29 & 12.1 \\
\hline
\end{tabular}

${ }^{1}$ ESO: Compulsory Secondary Education.

${ }^{2}$ Bachillerato: A levels.

\subsection{Mobile Use}

The descriptive analysis (Table 2) of the variables mobile use, emotional regulation (coping directed to emotion) and coping directed to the problem were distributed according to the normal curve as in the Kolmogorov Smirnov test.

Table 2. Means and Standard Deviations.

\begin{tabular}{llll}
\hline Variables & Groups & M & SD \\
\hline Use of Smartphone & & 107.65 & 37.51 \\
Emotional regulation (emotion-focused coping) & Cognitive Reappraisal facet & 3.53 & .64 \\
& Expressive Suppression facet & 2.85 & .86 \\
& Cognitive Approach Coping & 2.47 & .57 \\
Problem-focused coping & Behavioral Approach Coping & 2.20 & .63 \\
& Cognitive Avoidance Coping & 2.24 & .67 \\
\hline
\end{tabular}

\subsection{Types of Smartphone Use and Emotion-Oriented Coping}

The possibility was raised that the type of use of the Smartphone (excessive, occasional and habitual) would generate different scores in two types of coping aimed at emotion (emotional suppression and cognitive reassessment). For this purpose, an analysis of variance (ANOVA) of a factor with independent measures was carried out, but with no statistically significant differences, neither between the variables emotional suppression and excessive use, nor in cognitive reassessment based on occasional use or habitual use.

However, when performing a three-factor ANOVA (mobile phone use, gender and age) of independent measures with the variable emotional suppression, an unexpected result was found. The interaction between mobile phone use and age was significant for the emotional suppression variable $\mathrm{F}$ $(16.196)=2.41 ; \mathrm{p}=.003$. The post hoc tests of multiple comparisons show that the difference in means was significant between 12 and 17 years old.

Once the age variable was divided into three groups, from 12 to 13 (group 1), 14 to 15 (group 2) and 16 to 18 (group 3), the two-factor ANOVA (age and mobile) provided richer results at the same time, it corroborated those previously obtained in the interaction between the mobile variables and age with emotional suppression $\mathrm{F}(6.228)=2.95 ; \mathrm{p}=.009$, which was significant in the habitual users $\mathrm{F}(2.153)=3.28$; $\mathrm{p}=.040$, for age groups $1(12-13)$ and $3(16-18)$. In turn, the interaction for the variable emotional suppression was also significant among users at risk $\mathrm{F}(2.32)=3.32 ; \mathrm{p}=.035$. In this case, the differences were between group 1 (12-13) and group 2 (14-15) (Figure 1).

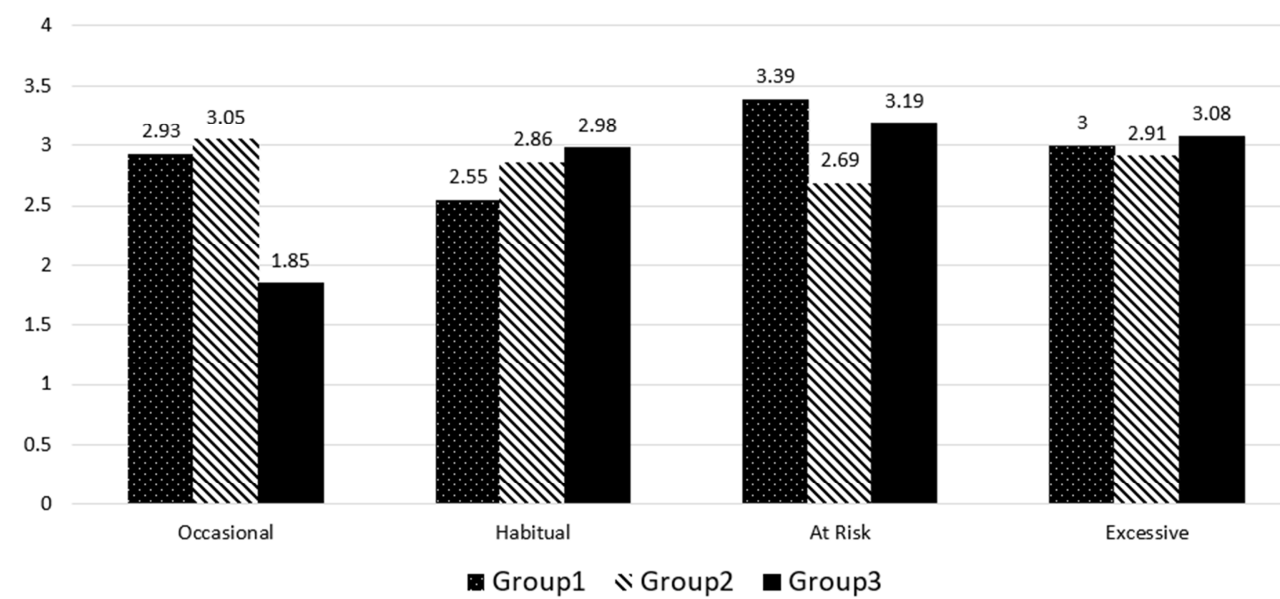

Figure 1. Estimated means of emotional suppression in the age groups 1 (12-13), 2 (14-15) and 3 (16-18), in different types of use of Smartphone, $N=240$. 


\subsection{Types of Smartphone Use and Problem-Oriented Coping}

It was expected to find differences between the two types of coping aimed at the problem (avoidance and approximation, cognitive and behavioral) depending on the use of the smartphone (occasional, habitual and excessive). For this, an independent measure factor ANOVA was carried out. Significant differences were found between the coping variables for cognitive avoidance (AEC) and the type of use of the Smartphone F (3.236) $=7.50 ; \mathrm{p}<.001$. The multiple comparison tests showed statistically significant differences between the AEC variable and occasional and habitual, occasional and at risk, and occasional and excessive use. The highest mean was in excessive use $(\mathrm{M}=2.63$; $\mathrm{SD}=.72)$. Between the confrontation by behavioral approximation $(\mathrm{AAC})$ and the type of use, significant differences were found $\mathrm{F}(3.236)=6.16 ; \mathrm{p}<.001$, more specifically between occasional and habitual use, and occasional and at risk. However, in this case, the highest mean was shown by the users at risk $(\mathrm{M}=2.35 ; \mathrm{SD}=.59)$ (Figure 2).

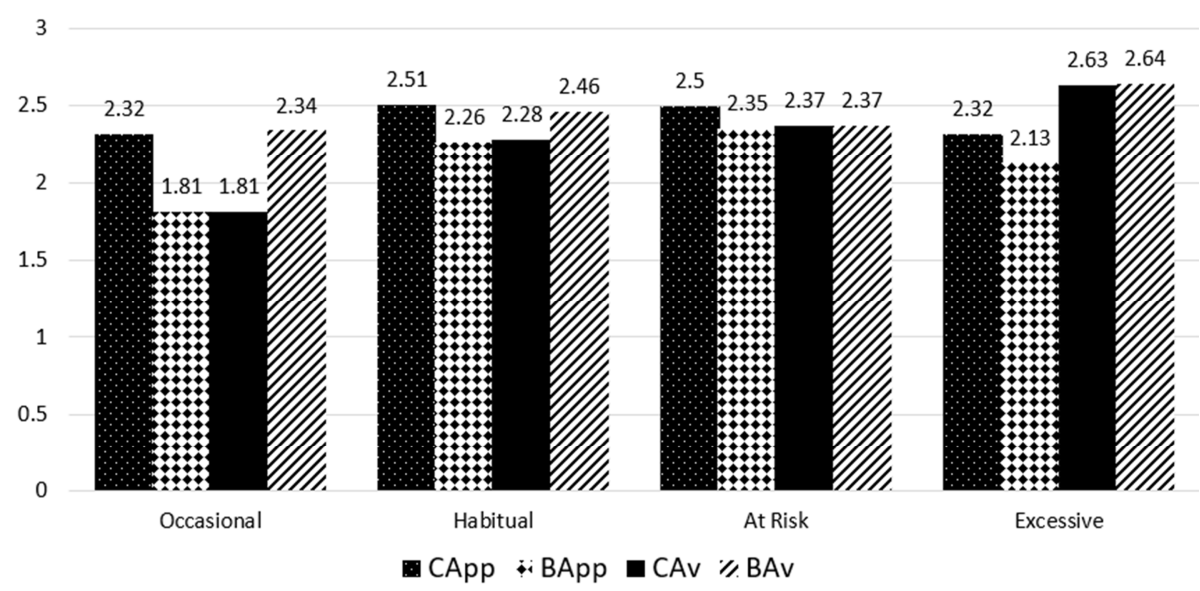

Figure 2. Estimated means of four types of problem-focused coping depending on the four types of Smartphone uses $(N=240)$. CApp $=$ Cognitive Approach Coping; BApp = Behavioral Approach Coping; CAv = Cognitive Avoidance Coping; BAv = Behavioral Avoidance Coping.

Table 3. The Independent Samples T-Text with Sex and Coping Variables.

\begin{tabular}{|c|c|c|c|c|c|}
\hline \multirow{2}{*}{ Coping } & Sex & Mean & \multicolumn{3}{|c|}{$t$-Test } \\
\hline & - & - & $d f$ & $t$ & $p$ \\
\hline \multirow{2}{*}{ Cognitive Approach Coping } & Man & 2.39 & \multirow{2}{*}{238} & \multirow{2}{*}{-2.03} & \multirow{2}{*}{.040} \\
\hline & Woman & 2.53 & & & \\
\hline \multirow{2}{*}{ Behavioral Approach Coping } & Man & 2.09 & \multirow{2}{*}{238} & \multirow{2}{*}{-2.28} & \multirow{2}{*}{.020} \\
\hline & Woman & 2.28 & & & \\
\hline \multirow{2}{*}{ Cognitive Avoidance Coping } & Man & 2.13 & \multirow{2}{*}{238} & \multirow{2}{*}{-2.23} & \multirow{2}{*}{.020} \\
\hline & Woman & 2.33 & & & \\
\hline \multirow{2}{*}{ Behavioral Avoidance Coping } & Man & 2.29 & \multirow{2}{*}{238} & \multirow{2}{*}{-3.14} & \multirow{2}{*}{.002} \\
\hline & Woman & 2.56 & & & \\
\hline
\end{tabular}

\subsection{The Gender and Excessive Use of Smartphone}

No significant differences were found between the sexes and excessive use of the smartphone.

\subsection{The Gender and Coping}

Women made greater use of the smartphone facing the emotional suppression $\mathrm{F}(1.196)=4.46 ; \mathrm{p}=.03$.

Significant differences were found between the gender and all coping strategies aimed at the problem, again women were who used them the most. The results are shown in Table 3.

\section{Discussion}

The relationship between the Smartphone use and the style of coping directed to emotion is a more studied issue $[8,29-$ 31]. In contrast, its connection with confrontation directed to the problem is not found in the publications related to the topic. The stage of adolescence is key in the development of the human being, so it is vital to analyze if the smartphone can be used as a facilitator for the different difficulties that may arise day to day. Therefore, the importance of this research falls on the findings that link the Smartphone with coping directed to the problem, which brings something very novel to teenagers' connection with this device.

The results confirming the differences between coping based on cognitive avoidance (aimed at the problem) and the excessive use of the Smartphone, show that adolescents may be using the Smartphone to avoid cognitively facing the complicated or problematic situations of their daily life. The differences between the forms of coping that give a more adequate response to problems, such as the behavioral approach, are related to the more adaptive uses of the Smartphone (occasional and habitual). However, those who 
are at risk of developing excessive use reflect a higher average than others in coping by the behavioral approach. Perhaps it is because the difference in means, despite being significant, is not very defined (Figure 2). Likewise, it could be explained that those subjects that make a high use of the mobile but does not become excessive, still resort to this type of coping strategy aimed at the problem. In fact, it is well known, that when young people face different daily events, they tend to increase the use of new technologies to manage their mood, compensate for social interaction and escape from reality [8]. The results confirm the recent theory of the compensatory use of Internet [30] suggesting that facing the need to deal with stressful events, different motivations leading to contact with Internet platforms arise, the choice of which to use will be based on cultural factors and expectations of satisfaction [31].

Regarding gender, there are no significant differences depending on the use. Both sexes tend to use the device in a similar way, which helps to clarify the controversial results that are reflected in the review $[13,32]$. Our results do not confirm other studies [33, 34]. It remains inconclusive if gender, as a variable, influences the patterns of use of the Smartphone. Some studies showed that men score a lot in excessive use, others in contrast tell us that women perceive themselves higher. Perhaps we can interpret this contradictory issue and justify our results, considering the natural immaturity of adolescent people. In fact, during adolescence there is a clear vulnerability for developing an excessive use of the smartphone. This is because the brain has not yet finished the maturing process of the areas responsible for decision-making, impulse control or risk-taking. The problem in teenagers is that they are more influenced by advertising campaigns, have less ability to judge the content they offer and also understand the smartphone as a status symbol.

The increase use in recent years has alarmed parents and teachers observing that the habits and customs they grew up with have been replaced by technological devices, which in many cases distract them from their learning processes [2]. Such a generation gap gives the adult a similar general image of adolescence regardless of gender. In fact, adults grew up in an environment that did not incorporate these communication devices, therefore the same image for both sexes, as all adolescents use it equally.

On the other hand, if differences between gender and coping are explored, it is observed that girls use significantly all the coping styles directed to the problem. The same happens with the strategy of emotional suppression (confrontation directed to the emotion). However, socially and culturally, it is usually expected that the female gender better manages their emotions and resorts less frequently to this type of strategy, focused on the response and, therefore, aimed at modulating the emotion already triggered. However, it is important to bear in mind that the participants of the sample reside in an area of medium-low socio-economic level.

Many teenagers neglect a face-to-face conversation by interrupting with a call or message. This fact affects their social relations and causes them to be more aware of the telephone links than the personal ones [35]. Therefore, some researchers suggest that this could help to understand the difficulties observed in adolescents when they have to talk face-to-face and put what they feel and think into words [36].

Different authors state that the smartphone has different meanings in the adolescents' lives. On the one hand, it interferes in a very relevant way in socialization as it allows us to define part of the adolescent's identity individually, based on personalizing it in different ways (colors, tones, etc.), and collectively, creating and maintaining a group language. On the other hand, it is part of daily life and is used as a mean of building social bonds and defining one's own space in relation to others [3]. It also acts as a privacy barrier against parents [2, $4,36]$. Some of the complicated situations described in the coping questionnaire (CRI-YF) reflected the seriousness of the family situation, and girls were who tended to show less concern when writing about it. Therefore, it is possible that a conflictive family and relational environment prevents adolescents from more adaptive handling of their emotions and more frequently resorting to emotional suppression.

\section{Conclusion}

It is important to continue contributing information to the existing relationship between the different uses of the smart mobile phone and coping directed to the problem. For this, the design of new instruments adapted to the current technological reality is essential. In turn, it would be interesting to also replicate this study with a more varied sample at a socio-demographic level.

\section{Acknowledgements}

The authors would like to thank all the high school teachers, staff and students who took part in the study.

\section{Conflict of Interest}

The authors declare that they have no conflict of interest.

\section{References}

[1] E. J. Pedrero Perez, M. T. Rodriguez Monge, and J. M. Sanchez de Leon, "Adiccion o abuso del telefono movil. Revision de la literatura," Adicciones, vol. 24, no. 2, pp. 139$152,2012$.

[2] E. Echeburúa, F. Labrador, and E. Becoña, Adicción a las nuevas tecnologías en adolescentes y jóvenes. Madrid: Pirámide, 2013.

[3] V. Oksaman and P. Rautiainen, "Toda mi vida en la palma de mi mano: la comunicación móvil en la vida diaria de niños y adolescentes de Finlandia," Estudios de Juventud vol. 57, no. 2, pp. 25-32, 2002.

[4] R. Ling, "Chicas adolescentes y jóvenes adultos varones: dos subculturas de teléfono móvil," Estudios de Juventud vol. 57, no. 2, pp. 33-46, 2002.

[5] M. Bian and L. Leung, "Linking Loneliness, Shyness, Smartphone Addiction Symptoms, and Patterns of Smartphone Use to Social Capital," Social Science Computer Review, vol. 33, no. 1, pp. 61-79, 2015/02/01 2014. 
[6] Y.-K. Lee, C.-T. Chang, Y. Lin, and Z.-H. Cheng, "The dark side of smartphone usage: Psychological traits, compulsive behavior and technostress," Computers in Human Behavior vol. 31, pp. 373-383, 2014/02/01/ 2014.

[7] H. Loowood, "Found technology: players as innovators in the making of machinima. ," in Digital youth, innovation, and the unexpected, T. McPherson, Ed. Cambridge: The MIT Press, 2008, pp. 165-196.

[8] L. Leung, "Stressful life events, motives for Internet use, and social support among digital kids," (in eng), Cyberpsychol Behav, vol. 10, no. 2, pp. 204-14, Apr 2007.

[9] Y. S. Yang, J. Y. Yen, C. H. Ko, C. P. Cheng, and C. F. Yen, "The association between problematic cellular phone use and risky behaviors and low self-esteem among Taiwanese adolescents," (in eng), BMC Public Health, vol. 10, p. 217, Apr 2010.

[10] S. Thomée, A. Härenstam, and M. Hagberg, "Mobile phone use and stress, sleep disturbances, and symptoms of depression among young adults - a prospective cohort study," BMC Public Health, vol. 11, no. 1, p. 66, 2011/01/31 2011.

[11] K. S. Young, "Internet Addiction: A New Clinical Phenomenon and Its Consequences," American Behavioral Scientist, vol. 48, no. 4, pp. 402-415, 2004/12/01 2004.

[12] K. C. Lee, "Mobile phone text messaging overuse among developing world university students AU - Perry, Stephen D," Communicatio, vol. 33, no. 2, pp. 63-79, 2007/11/01 2007.

[13] N. Dlodlo, "Salient indicators of mobile instant messaging addiction with selected socio-demographic attributes among tertiary students in South Africa," South African Journal of Psychology, vol. 45, no. 2, pp. 207-222, 2015/06/01 2015.

[14] A. Bener, H. S. Al-Mahdi, P. J. Vachhani, M. Al-Nufal, and A. I. Ali, "Do excessive internet use, television viewing and poor lifestyle habits affect low vision in school children?," Journal of Child Health Care, vol. 14, no. 4, pp. 375-385, 2010/12/01 2010 .

[15] J. E. Buckner, C. M. Castille, and T. L. Sheets, "The Five Factor Model of personality and employees' excessive use of technology," Computers in Human Behavior, vol. 28, no. 5, pp. 1947-1953, 2012/09/01/2012.

[16] G. Martinotti et al., "Problematic mobile phone use in adolescence: A cross-sectional study," Journal of Public Health vol. 19, no. 6, 2010.

[17] H. T. Chen and Y. Kim, "Problematic use of social network sites: the interactive relationship between gratifications sought and privacy concerns," (in eng), Cyberpsychol Behav Soc Netw, vol. 16, no. 11, pp. 806-12, Nov 2013.

[18] J.-L. Wang, H.-Z. Wang, J. Gaskin, and L.-H. Wang, "The role of stress and motivation in problematic smartphone use among college students," Computers in Human Behavior, vol. 53, pp. 181-188, 2015/12/01/2015.

[19] J. Lemon, "Can we call behaviors addictive," Clinical Psychologist vol. 6, no. 2, pp. 44-49, 2002.

[20] L. Widyanto and M. Griffiths, "“Internet addiction": a critical review," International Journal of Mental Health and Addiction vol. 4, no. 1, pp. 31-51, 2006.

[21] C. Peters and L. Malesky, "Problematic Usage Among Highly-Engaged Players of Massively Multiplayer Online
Role Playing Games " CyberPsychology \& Behavior vol. 11, no. 4, pp. 481-484, 2008.

[22] M. Griffiths, "Technological addictions," Clinical Psychology Forum vol. 76, pp. 14-19, 1996.

[23] O. López-Fernández, M. Honrubia-Serrano, and M. FreixaBlanxart, "Adaptación española del "Mobile Phone Problem Use Scale" para población adolescente," (in Español), Adicciones, vol. 24, no. 2, pp. 123-130, 2012.

[24] J. Gross and O. John, "Individual differences in two emotion regulation processes: implications for affect, relationships, and well-being," Journal of Personality \& Social Psychology vol. 85, pp. 348-362 2003.

[25] E. Gullone and J. Taffe, "The Emotion Regulation Questionnaire for Children and Adolescents (ERQ-CA): A Psychometric Evaluation," Psychological Assessment vol. 24, no. 2, pp. 409-417, 2012.

[26] R. Cabello, J. M. Salguero, P. Fernández-Berrocal, and J. J. Gross, "A Spanish Adaptation of the Emotion Regulation Questionnaire," European Journal of Psychological Assessment, vol. 29, no. 4, pp. 234-240, 2013/01/01 2013.

[27] R. Moos, Coping Responses Inventory: CRI from Adults. Professional Manual. Odessa: TX: Psychological Assessment Resources 1993.

[28] P. Ongarato, G. Iglesia, J. Stover, and M. Fernández, "Adaptación de un inventario de estrategias de afrontamiento para adolescentes y adultos: an adaptation to adolescent and adult population," Anuario de investigaciones vol. 16, pp. 383-391, 2009.

[29] S.-I. Chiu, "The relationship between life stress and smartphone addiction on taiwanese university student: A mediation model of learning self-Efficacy and social selfEfficacy," Computers in Human Behavior, vol. 34, pp. 49-57, 2014/05/01/ 2014.

[30] D. Kardefelt-Winther, "A conceptual and methodological critique of internet addiction research: Towards a model of compensatory internet use," Computers in Human Behavior, vol. 31, pp. 351-354, 2014/02/01/ 2014.

[31] T. Ruggiero, "Uses and Gratifications Theory in the 21st Century AU," Mass Communication and Society, vol. 3, no. 1, pp. 3-37, 2000/02/01 2000 .

[32] S. Perry and K. Lee, "Mobile phone text messaging overuse among developing world university students AU - Perry, Stephen D," Communicatio, vol. 33, no. 2, pp. 63-79, 2007/11/01 2007.

[33] N. S. Baron, "See you Online: Gender Issues in College Student Use of Instant Messaging," Journal of Language and Social Psychology, vol. 23, no. 4, pp. 397-423, 2004/12/01 2004.

[34] X. Carbonell, A. Chamarro, M. Griffiths, U. Oberst, R. Cladellas, and A. Talarn, "Problematic Internet and cell phone use in Spanish teenagers and young students," (in Desconocido), Anales de Psicología, vol. 28, no. 3, pp. 789-796, 2012.

[35] J. Adès and M. Lejoyeux, Las nuevas adicciones: Internet, sexo, deporte, compras, trabajo, dinero. Barcelona: Kairós, 2003.

[36] S. Lorente, "Juventud y teléfonos móviles: Algo más que una moda," Estudios de Juventud vol. 57, no. 2, pp. 9-24, 2002. 